OPEN ACCESS

Edited by:

Giuseppe Di Vita

University of Turin, Italy

Reviewed by:

Marco Medici,

University of Bologna, Italy

Masoud Yazdanpanah,

Agricultural Sciences and Natural

Resources University of

Khuzestan, Iran

*Correspondence:

Agnes Emberger-Klein

agnes.emberger-klein@hswt.de

Specialty section:

This article was submitted to Nutrition and Sustainable Diets,

a section of the journal

Frontiers in Sustainable Food Systems

Received: 25 August 2021 Accepted: 23 November 2021 Published: 14 December 2021

Citation:

Emberger-Klein A, Schöps J and Menrad K (2021) The Influence of Climate Attitudes and Subjective and

Social Norms on Supermarket

Consumers' Intention Toward Climate-Friendly Food Consumption. Front. Sustain. Food Syst. 5:764517. doi: 10.3389/fsufs. 2021.764517

\section{The Influence of Climate Attitudes and Subjective and Social Norms on Supermarket Consumers' Intention Toward Climate-Friendly Food Consumption}

\author{
Agnes Emberger-Klein ${ }^{1 *}$, Johanna Schöps ${ }^{2}$ and Klaus Menrad ${ }^{1}$ \\ ${ }^{1}$ Chair of Marketing and Management of Biogenic Resources, Weihenstephan-Triesdorf University of Applied Sciences, \\ Technical University of Munich Campus Straubing for Biotechnology and Sustainability, Straubing, Germany, ${ }^{2}$ GreenSurvey \\ Institut Für Marktforschung Prof. Dr. Klaus Menrad GmbH, Straubing, Germany
}

Consumers can reduce greenhouse gas (GHG) emissions by changing their individual diets. Moreover, several studies showed that a positive intention to make climate-friendly food choices can be found among private consumers. Accordingly, the aim of this study was to analyze the factors, which influence supermarket consumers' behavioral intentions toward climate-friendly food consumption. For the analysis data from a face-to-face in-store survey in the southern Germany was used. The study was able to verify a large positive effect of Climate Attitudes and a medium positive effect of Subjective and social Norms on consumers' behavioral intention toward climate-friendly food consumption using an extended model of the Theory of Reasoned Action and structural equation modeling to analyze the data. However, the presumed direct effect of Perceived Behavioral Competency on this issue could not be proven. Based on the results strategies for the enhancement of climate-friendly food consumption are suggested.

Keywords: food consumption, GHG emissions, consumer, theory of reasoned action, structural equation modeling

\section{INTRODUCTION}

In 2021 almost one fifth of European citizens evaluates climate change as the most serious problem in the world, just ahead of poverty, hunger and lack of drinking water as well as the spread of infectious diseases. Most of the participants of the Eurobarometer-study perceive actions against climate change to be the responsibility of national governments. However, more than $40 \%$ of the participants believe in personal responsibility with regard to climate change-related activities (European Union, 2021). On the individual level personal actions in the area of food, mobility and housing are useful, since these fields significantly impact the emissions of greenhouse gas (GHG) emissions (Faber et al., 2012). Behavioral change options in the food domain are e.g., to eat more local food, to reduce imported food, to reduce food waste, to eat healthy or to change to a vegetarian diet (Faber et al., 2012). Eating more locally-produced food has positive impacts on transportation emissions. Considering the change to a vegetarian diet, Scarborough et al. (2014) showed that the mean GHG emissions per 2,000 kcal diet of heavy consumers of meat are almost twice as high as those of vegetarians. Green et al. (2015) found that a reduction of up to $40 \%$ of $\mathrm{CO}_{2}$ 
emissions can be reached by switching to a diet which contains e.g., fewer animal products and more fruit, vegetables and cereals. According to these authors, higher reductions are also possible. However, this would require radically altered and narrow diets (Green et al., 2015). Thus, these studies and others (e.g., Hedenus et al., 2014) show that alternative personal diets can reduce a serious amount of GHG emissions. Nevertheless, Mäkiniemi and Vainio (2013) point out that climate-friendly food consumption seems to be challenging for consumers due to aspects like a lack of consumers' awareness of their environmental impact, a lack of willingness to reduce meat consumption or a perceived difficulty to follow a plant-based diet. Faber et al. (2012) summarize that knowledge-based barriers, unconscious behavior, structural and physical, and cultural barriers exist for climatefriendly food consumption. In spite of these barriers different studies documented a positive intention of consumers to make climate-friendly food choices (e.g., eat local, eat seasonal or reduce meat consumption) (Tobler et al., 2012; Mäkiniemi and Vainio, 2013; Sundblad et al., 2014; van der Linden, 2014).

Given the described mitigation potential of personal diets and the described positive intention to act, it is important to know the factors which influence the intention toward climate-friendly food consumption. Knowing these factors it is possible to derive measures for behavioral change. This is possible since different well-established social psychology theories [e.g., Theory of Reasoned Action (Fishbein and Ajzen, 1975); Theory of Planned Behavior (Ajzen, 1985)] show that intention is a direct predictor of behavior. When analyzing intention influencing factors it is especially desirable to follow a theory-driven approach, since research in this area has often been rather descriptive or explanatory (Tikir and Lehmann, 2011; van der Linden, 2014). While there are studies using established social psychology theories to explain climate-friendly behavior in other fields (e.g., transportation) (Bamberg et al., 2007; Tikir and Lehmann, 2011), such studies are lacking in the area of food consumption. Thus, the aim of this study was to analyze the factors, which influence supermarket consumers' behavioral intentions toward climate-friendly food consumption using a theory-driven approach, namely an extended model of the Theory of Reasoned Action (TRA). TRA was used, because strong predictive utility of the model was proven for various fields of human behavior (Sheppard et al., 1988). Structural equation modeling was used to analyze data from a face-to-face, in-shop consumer study conducted in southern Germany. Within the survey, we were especially interested in the consumption of fruit and vegetables, since substituting fruit and vegetables for animal products can save substantial amounts of GHG emissions (Scarborough et al., 2014; Green et al., 2015).

The remainder of this study is structured as follows: In the next section a model explaining climate-friendly food consumption is developed on the basis of relevant literature and theory. This is followed by a description of the used methodology and a presentation of the results. The manuscript ends with a discussion of the results as well as the major conclusions.

\section{THEORETICAL BACKGROUND AND HYPOTHESES}

Since the 1970s environmental psychologists have tried to detect the factors which predict environment-related behavior, which is closely related to climate-friendly behavior ( $\mathrm{R}$. Gifford et al., 2011). One important theory in this respect is the Theory of Reasoned Action (TRA) (Fishbein and Ajzen, 1975), which assumes a person's intention to perform or not perform a specific behavior as the direct determinant of the behavior (see Figure 1).

TRA consists of two determinants of intention: attitude toward the behavior and subjective norm. Attitude is personal in nature, while subjective norm reflects the social influence. Thus, individuals intend to behave in a certain way when they positively appraise the behavior and when they think that people who are important to them believe they should behave in this way (Fishbein, 1979). The adequacy of the TRA to explain environment-related behavior has been proven empirically in different fields, like e.g., purchase intention for green or energyefficient products (Ha and Janda, 2012; Paul et al., 2016), use of green information technology (Mishra et al., 2014) or intention to conserve water in lodging context (Untaru et al., 2016). In this respect all the mentioned studies as well as others (e.g., Tikir and Lehmann, 2011) found a positive effect of attitude and subjective norm on the respective intention to behave environmentally friendly (Ha and Janda, 2012; Paul et al., 2016; Untaru et al., 2016). Additionally, especially for Germany Dirks et al. (2010) showed that general social norms have a strong correlation with the intention of climate-friendly behavior.

Thus, following the TRA-model and the described empirical findings for Germany, the following hypotheses are formulated regarding the influence of Subjective and social Norms and Climate Attitudes on the intention of climate-friendly food consumption behavior (see also Figure 2):

- The stronger the Subjective and social Norms regarding climate-friendly food consumption the higher the intention of climate-friendly food consumption (H1).

- The more positive the Climate Attitudes, the higher the intention of climate-friendly food consumption (H2).

Due to the mitigation potential of substituting fruit and vegetables for animal products this study is especially interested in the consumption of fruit and vegetables. However, the actual reduction potential of groceries is effected by the substituted

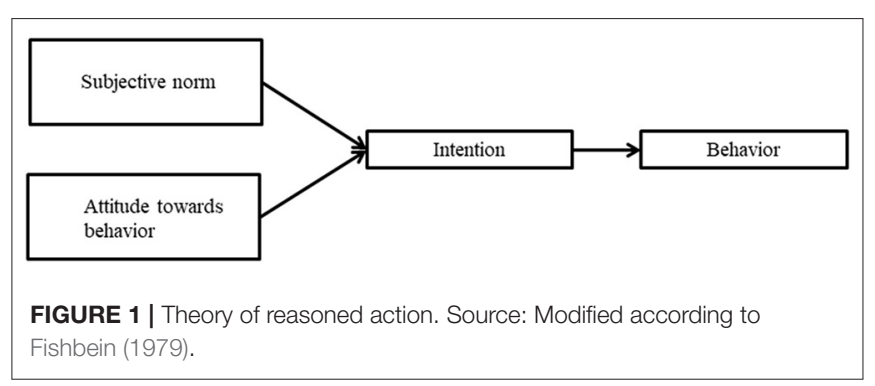




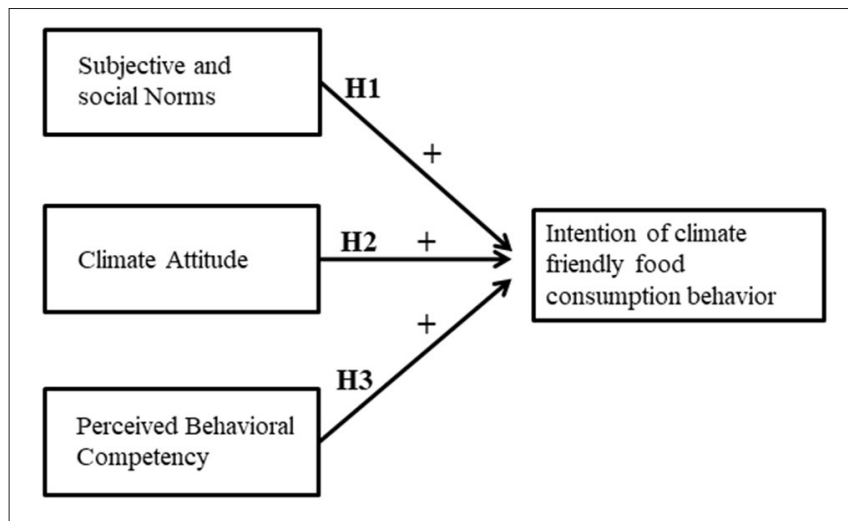

FIGURE 2 | Developed model for the Intention of climate-friendly food consumption behavior.

products, since large variations exist in the GHG intensity per unit of animal and vegetable food products (Hedenus et al., 2014). In the case of fruit and vegetables the variation in $\mathrm{CO}_{2}$ emissions e. g between different production systems, seasons, places of production or distribution systems could be shown by different authors (e.g., Theurl, 2008; Kögl and Tietze, 2010; British Standards Institution, 2012; Soode et al., 2015). However, for many consumers it is difficult to identify high and low carbonemitting groceries (Sharp and Wheeler, 2013). Given this fact, we argue that behavioral competency regarding the identification of climate-friendly food, especially fruit and vegetables, can directly affect the intention to consume climate-friendly food. We base this assumption on different studies which indicate a positive influence of competency on environmentally responsible behavior. For example, Corral-Verdugo (1997) reported that re-using and recycling competencies can successfully predict observed re-use/recycling behavior; De Young (1988) could show that procedural-knowledge is helpful in differentiating observed recyclers from non-recyclers and Aitken et al. (2016) found that perceived environmental competency directly influences frequency of difficult pro-environmental behaviors. Following Ajzen (1991)'s request for model extension and in analogy to other studies (e.g., Untaru et al., 2016) an extended version of the pure TRA-model is evaluated in this study. The following hypotheses regarding the influence of behavioral competency on the intention toward climate-friendly food consumption behavior is assessed (see also Figure 2):

- The higher the Perceived Behavioral Competency regarding the identification of climate-friendly fruits and vegetables, the higher the intention of climate-friendly food consumption (H3).

\section{MATERIALS AND METHODS}

\section{Procedure}

The analysis is based on data from a quantitative consumer study conducted in the spring of $2014(n=413)$. The survey dealt with the topic "Consumption of fruit and vegetables" and had a special focus on apples and tomatoes. The target group consisted of individuals age 16 and older, who are the grocery shoppers for their household and who at least occasionally buy apples and tomatoes. Data was collected by means of computer assisted personal interviews, which took place in four cities with differing numbers of inhabitants (Reutlingen $n=106$, Pfullendorf $n=99$, Stuttgart-Vaihingen $n=108$, Weil der Stadt $n=100$ ) in southern Germany using convenience sampling. The interviews were carried out by the first author plus seven instructed and mostly in interviewing very experienced students in four supermarkets and convenience stores belonging to the biggest German food retailer, the EDEKA group. To include all types of shopping behavior and households in the survey, the interviews were spread over all possible shopping days of one week (Monday to Saturday) and the different times of the day. The interviews lasted on average $20.7 \mathrm{~min}$ and took place within the supermarkets or near the checkout area. Before the interviews, respondents were informed about the content of the survey and that the interviews will be kept strictly confidential and will not be used for any purpose other than the scientific project. Upon completion of the survey, respondents received a voucher of a local bookstore (worth $10 €$ ) as incentive.

\section{Measures}

Table 1 summarizes the wording of the items, their labels and their sources, which were used to operationalize the theoretical constructs of this survey. All items were rated on a five-point Likert-like Scale from I absolutely agree $(=1)$ to I do not agree (=5). The Intention of climate-friendly food consumption behavior (short: Intention) was operationalized using two items. One of them describes the personal importance of contributing to climate protection (intent_importance). The second emphasizes that consumers strongly aim to contribute more to climate protection in the future (intent_future). Subjective and social Norm (SN) was measured with two items (norm_all, norm_close). All of the described items originated from the study of Dirks et al. (2010) and were formulated with a focus on food consumption. Dirks et al. (2010) found in a representative study $(n=3.284)$ that the item sets used are robust and very well-suited for application in studies on climate-friendly consumer behavior in German. They also recommended modifying the developed items according to the subject of the study at hand. The four items regarding Climate Attitude (CA) are a modified and shortened version of the Green Consumption Values developed by Haws et al. (2014) (attitude_importance, attitude_decision, attitude_purchasehabit, attitude_concern). The selection of the four items from the original six items was based on the data of an online study [ $n$ $=71$, Kainz et al. (2014)], in which the original items of Haws et al. (2014) were used and reliability analysis was performed. To adapt the items of the original scale to the context of the climate-friendly food consumption behavior, we replaced the term "environment" with "climate" in the following three items: attitude_importance, attitude_decision, attitude_purchasehabit. Items for the Perceived Behavioral Competency (PBC) construct were developed based on the study of Mäkiniemi and Vainio (2013). In their survey the authors identified six climate-friendly 
TABLE 1 | Operationalization of the constructs in the survey.

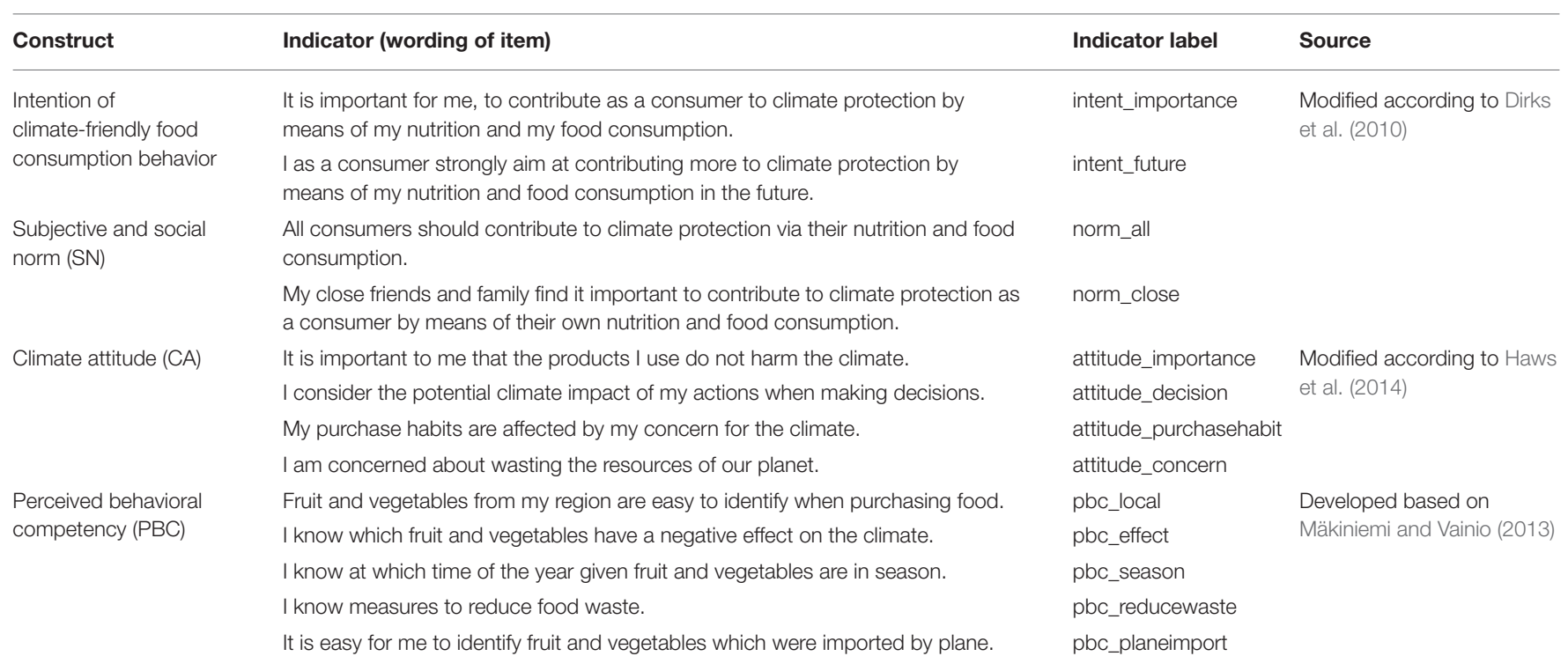

Source: own depiction.

food choices using a literature review. On the basis of five of these strategies, items were formulated which express the PBC to choose climate-friendly produce (see Table 1) (pbc_local, pbc_effect, pbc_season, pbc_reducewaste, pbc_planeimport).

\section{Data Analysis}

In this study structural equation modeling was used. This method is currently seen as a standard for simultaneously exploring complex causal connections between latent, exogenous or endogenous variables (Huber et al., 2007). The partial least squares (PLS) approach was chosen for this study because it is able to represent formative as well as reflexive constructs. Therewith, key driver constructs can be identified and PLS does not postulate normally distributed data (Hair et al., 2017). SmartPLS Version 3 Software (Ringle et al., 2015) was used for data analysis.

While the inner path model represents the causal connections between latent variables in a path diagram, the outer exogenous model illustrates the connections between manifest indicators which determine independent latent variables. The outer endogenous model displays the connections between manifest indicators that fix dependent latent variables (Nitzl, 2010). Multiple causal connections between variables can thus be designed and tested empirically by using structural equation modeling (Boßow-Thies and Panten, 2009).

According to Henseler et al. (2009), the PLS Algorithm can be seen as a sequence of regressions in terms of weighted vectors. Weights are used as auxiliary variables in order to fix estimation parameters. Within an iterative process (least squares method), precise values can be determined for latent variables (Huber et al., 2007). As a first step, construct values for each latent variable are identified. Dependent on a reflexive or formative operationalization of the construct, the correlation value or regression coefficient is used as a weighting factor for proximate latent variables within the path weighting scheme. Second, the construct value for latent variables within the inner model is calculated. Subsequently, the outer weights are estimated. While a principal component analysis is run for reflexive constructs, a multiple regression analysis is calculated for formative constructs. The algorithm is completed with the outer approach of the latent variable values. The path coefficients can then be calculated creating mean values (Henseler et al., 2009).

\section{RESULTS}

\section{Description of the Variables}

Table 2 shows the key socio-demographic (SOD) characteristics of the sample, and for the purpose of comparison it also includes information on the relevant population (householder). Approximately two thirds of the respondents were female, which corresponds to the fact that in Germany women are still the primary purchasers of household goods (Verbraucheranalyse, 2012). The share of young people ( $<30$ years) and larger households ( $3+$ individuals) was higher in the sample than in the relevant population. Additionally, there is an overrepresentation of people with higher education and higher occupation groups (e.g., senior executives/chief officers).

The results of the items, which operationalized the intention of climate-friendly food consumption, are summarized in Table 3 (total) and Table 4 (by socio-demographics).

In total, consumers show a high Intention to behave climate-friendly regarding food consumption according to this study. $76.8 \%$, respectively, 68.3\% (absolutely) agree with the Intention-statements. However, there are also statistically significant differences between some SOD groups: Women have a higher Intention of climate-friendly food consumption 
than men. The same is true for older $(30+$ years $)$ compared to younger ( $<30$ years) consumers. In tendency there are also differences for at least one Intention-item between the occupation and education groups: By trend, is the importance to contribute to climate protection lowest for people who have never been employed and highest for senior executive/chief officers. Additionally, the aim to contribute more to climate protection in future is highest for people with a medium level of education.

TABLE 2 | Socio-demographic characteristics of the sample and the population.

\begin{tabular}{|c|c|c|c|}
\hline & & Sample & Householder $^{\mathrm{a}}$ \\
\hline$n$ & & 413 & \\
\hline \multirow[t]{2}{*}{ Gender (\%) } & Female & 69.0 & 67.3 \\
\hline & Male & 31.0 & 32.7 \\
\hline \multirow[t]{3}{*}{ Age (\%) } & $16-29$ years & 24.7 & 11.2 \\
\hline & 30-49 years & 31.2 & 34.5 \\
\hline & $50+$ years & 44.1 & 54.3 \\
\hline \multirow[t]{3}{*}{ Size of household (\%) } & 1 Individual & 13.3 & 26.3 \\
\hline & 2 Individuals & 39.5 & 38.1 \\
\hline & $3+$ Individuals & 47.2 & 35.6 \\
\hline \multirow[t]{3}{*}{ Education ${ }^{\mathrm{b}}(\%)$} & Low & 3.4 & 11.9 \\
\hline & Medium & 65.9 & 70.8 \\
\hline & High & 30.8 & 17.3 \\
\hline \multirow[t]{5}{*}{ Occupation (\%) } & $\begin{array}{l}\text { Self- } \\
\text { employed/freelancer/ } \\
\text { agriculturalist }\end{array}$ & 13.1 & 8.6 \\
\hline & $\begin{array}{l}\text { Senior executive/chief } \\
\text { officer }\end{array}$ & 15.0 & 8.2 \\
\hline & $\begin{array}{l}\text { White-collar } \\
\text { worker/public officer }\end{array}$ & 47.2 & 57.5 \\
\hline & $\begin{array}{l}\text { Skilled worker/unskilled } \\
\text { worker }\end{array}$ & 10.4 & 20.9 \\
\hline & Never been employed & 14.3 & 4.8 \\
\hline
\end{tabular}

aIndividuals 16+ years from Baden-Württemberg who are the purchaser of household goods and who bought food from EDEKA during the last months (Source: Verbraucheranalyse, 2012); b Low: no/does not yet have a certificate of graduation, Certificate of Secondary Education (CES) without apprenticeship; Medium: CES with apprenticeship, secondary school, higher education entrance qualification; High: higher education.

Source: Emberger-Klein et al. (2015).
Table 5 shows the frequency distribution and means of all statements which operationalise the three exogenous variables as well as their correlations with both Intention-items. We find a high agreement with the Subjective and social Normitem that all consumers should contribute to climate protection as well as to two Climate Attitude-items (attitude_importance, attitude_concern). Thus, for most consumers it is important to use products which do not harm the climate and the majority of

TABLE 4 | Intention by sociodemographic variables $(n=413)$.

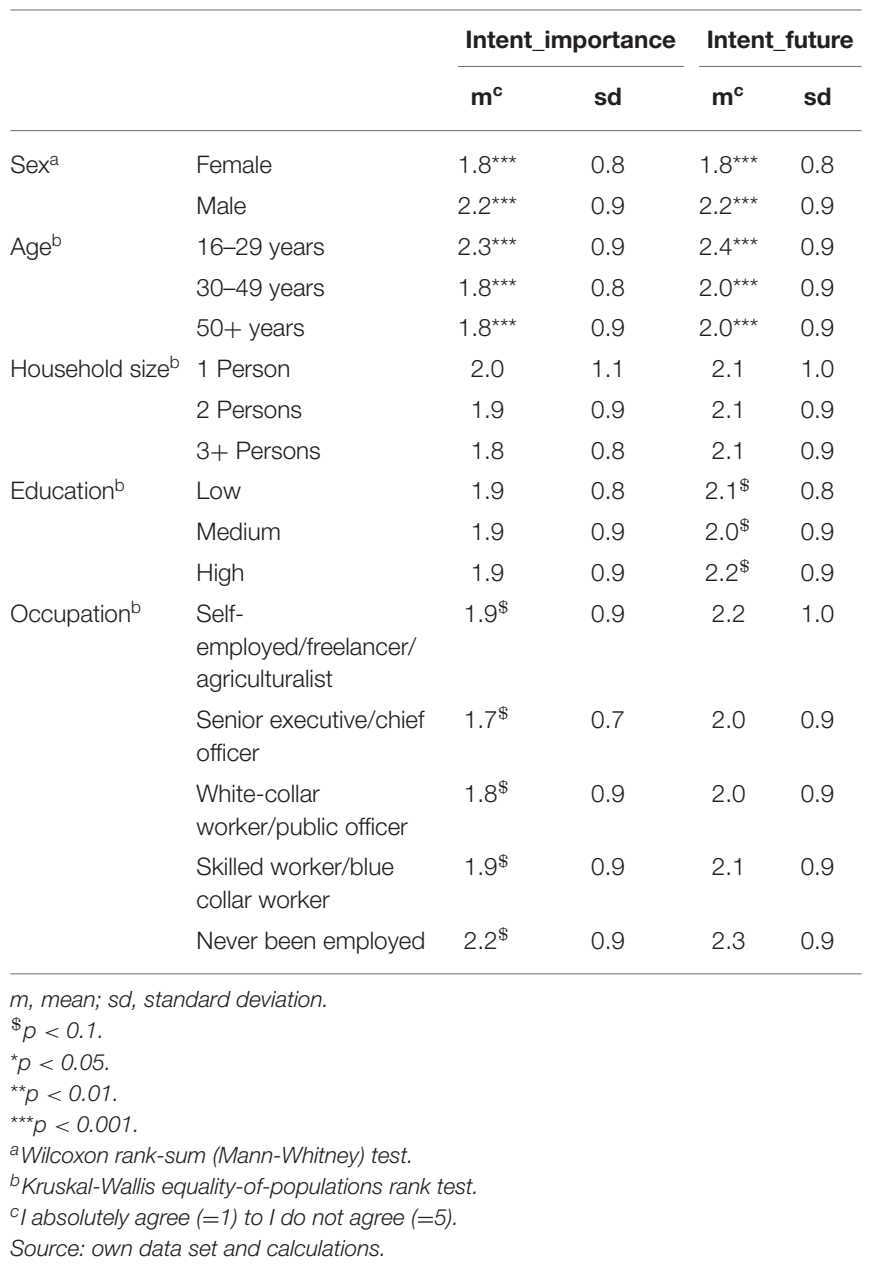

TABLE 3 | Description of the variable Intention (frequencies-agreement in $\%, n=413$ ).

\begin{tabular}{|c|c|c|c|c|c|}
\hline & Agreement $^{a}$ & Indifference ${ }^{b}$ & No agreement ${ }^{c}$ & m & sd \\
\hline $\begin{array}{l}\text { It is important for me, to contribute as a consumer to climate protection by } \\
\text { means of my nutrition and my food consumption (intent_importance). }\end{array}$ & 76.8 & 19.1 & 4.1 & 1.9 & 0.9 \\
\hline $\begin{array}{l}\text { I as a consumer strongly aim at contributing more to climate protection by } \\
\text { means of my nutrition and food consumption in the future (intent_future). }\end{array}$ & 68.3 & 24.7 & 7.0 & 2.1 & 0.9 \\
\hline
\end{tabular}

$m$, mean; sd, standard deviation.

al (absolutely) agree (= 1 or 2).

${ }^{b}$ Neither agree nor disagree $(=3)$.

cl (somewhat) do not agree (= 4 or 5 ).

Source: own data and calculations. 
TABLE 5 | Description of all items which operationalize the exogenous variables and correlation of the variables with Intention (Frequencies-agreement in \%, $n=413$ ).

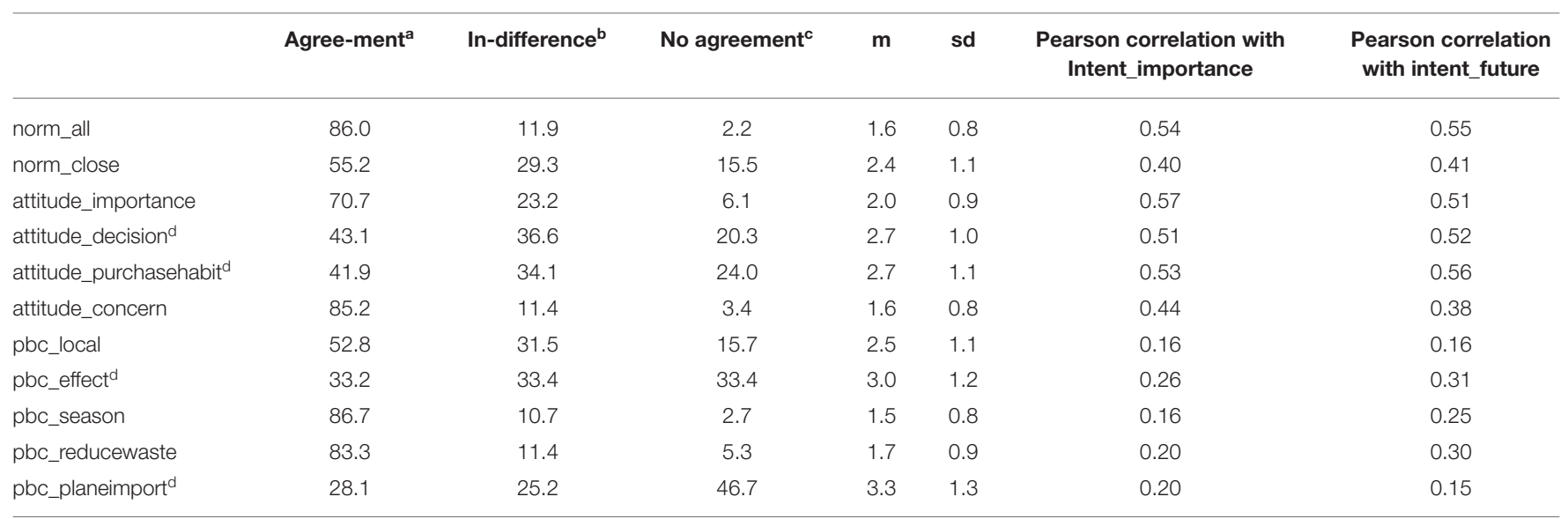

m, mean; sd, standard deviation.

al (absolutely) agree (=1 or 2).

${ }^{b}$ Neither agree nor disagree (3).

cI (rather) not agree (4 or 5).

${ }^{d}$ Data follows a normal distribution (Shapiro-Wilks test).

Source: own data set and calculations.

consumers are concerned about wasting our planet's resources. In contrast, the agreement with the statements dealing with the consideration of potential climate impacts as well as purchase habits is much lower. The correlations of all Attitude- or Subjective and social Norm-related statements with the Intentionitems are medium to large. Consumers state a high Perceived Behavioral Competence regarding the growing season of different produce as well as regarding measures to reduce food waste. However, they feel less qualified to identify locally produced food or produce imported by plane as well as regarding the effect of different fruit and vegetables on the climate. The correlations of these statements with the Intention-items are small to medium. Additionally, Table 5 shows that the distribution of most of the items does not follow normality.

\section{Results of the Structural Equation Modeling \\ Evaluation of the Measurement Model}

To evaluate the measurement model the reflective construct Intention and the formative constructs Subjective and social Norms, Climate Attitudes and Perceived Behavioral Competency were separately assessed following the recommendations of Hair et al. (2017).

To evaluate the reflective construct Intention internal consistency and convergent validity was checked. Assessed criteria as well as desired values are summarized in Table 6. An evaluation of discriminant validity was not applicable, since we have only one reflective construct. Internal consistency was proven due to a Cronbach's alpha value of 0.806 , respectively, composite reliability value of 0.911 . Convergent validity, which describes the extent to which a measure correlates positively with alternative measures of the same construct, was assessed using indicator reliability by observing the outer loadings as well as the average variance extracted (AVE) (Hair et al., 2017). Both outer
TABLE 6 | Evaluation of reflective construct: Intention.

\begin{tabular}{|c|c|c|}
\hline & Evaluation criteria & Estimated parameters \\
\hline \multirow{2}{*}{$\begin{array}{l}\text { Internal } \\
\text { consistency } \\
\text { reliability }\end{array}$} & $\begin{array}{l}\text { Cronbach's alpha: desired } \\
\text { value: }>0.7\end{array}$ & 0.806 \\
\hline & $\begin{array}{l}\text { Composite reliability: } \\
\text { desired value: }>0.6 \text { and } \\
<0.95\end{array}$ & 0.911 \\
\hline \multirow[t]{4}{*}{ Convergent validity } & $\begin{array}{l}\text { Indicator reliability: outer } \\
\text { loadings ( } \mathrm{m}, \mathrm{sd}, p \text {-value); } \\
\text { desired value }>0.7\end{array}$ & \\
\hline & - intent_importance & $\begin{array}{c}0.916 \\
(0.915,0.010, p<0.000)^{a}\end{array}$ \\
\hline & - intent_future & $\begin{array}{c}0.915 \\
(0.914,0.010, p<0.000)^{a}\end{array}$ \\
\hline & $\begin{array}{l}\text { Average variance extracted } \\
\text { (AVE): desired value }>0.5\end{array}$ & 0.837 \\
\hline
\end{tabular}

m, mean; sd, standard deviation.

a Complete bootstrapping option: no significant sign changes, 5,000 samples.

Source: own data and calculations.

loadings $(0.916,0.915)$ are above the desired value of 0.7 , which documents sufficient levels of indicator reliability. In addition, the AVE-value of 0.837 confirms convergent validity.

To assess the parameter estimates related to the three formative constructs Subjective and social Norm, Climate Attitude, and Perceived Behavioral Competency presence of collinearity among indicators using variance inflation factor (VIF) and significance of relevant indicator weights was checked. Results are summarized in Table 7. Since all VIF values are smaller than a threshold of 5, collinearity is not at a critical level. Complete bootstrapping (method: no significant sign changes, 5,000 samples) was used to determine if outer weights are significantly different from zero. All Subjective and 
TABLE 7 | Evaluation of the formative constructs.

\begin{tabular}{|c|c|c|c|c|c|c|c|c|}
\hline \multirow[t]{2}{*}{ Construct } & \multirow{2}{*}{$\begin{array}{l}\text { Indicator } \\
\text { Desired value }\end{array}$} & \multirow{2}{*}{$\begin{array}{l}\text { Outer weight } \\
\quad>0.1\end{array}$} & \multirow[t]{2}{*}{$\mathbf{m}^{\mathrm{a}}$} & \multirow[t]{2}{*}{$s d^{a}$} & \multirow[t]{2}{*}{$p$-value ${ }^{a}$} & \multirow[t]{2}{*}{$\begin{array}{c}\text { Confidence interval }{ }^{a, b} \\
(2.5 \% ; 97.5 \%)\end{array}$} & \multirow{2}{*}{$\begin{array}{l}\text { VIF } \\
<5\end{array}$} & \multirow[t]{2}{*}{$\begin{array}{l}\text { Outer } \\
\text { loading }\end{array}$} \\
\hline & & & & & & & & \\
\hline \multirow[t]{2}{*}{ Subjective and social norm (SN) } & norm_all & 0.781 & 0.779 & 0.050 & 0.000 & $(0.671 ; 0.867)$ & 1.1 & 0.924 \\
\hline & norm_close & 0.407 & 0.407 & 0.067 & 0.000 & $(0.278 ; 0.538)$ & 1.1 & 0.684 \\
\hline \multirow[t]{4}{*}{ Climate attitude (CA) } & attitude_importance & 0.443 & 0.442 & 0.069 & 0.000 & $(0.304 ; 0.578)$ & 1.4 & 0.817 \\
\hline & attitude_decision & 0.291 & 0.288 & 0.060 & 0.000 & $(0.179 ; 0.413)$ & 2.0 & 0.783 \\
\hline & attitude_purchasehabit & 0.330 & 0.329 & 0.066 & 0.000 & $(0.203 ; 0.458)$ & 2.1 & 0.828 \\
\hline & attitude_concern & 0.220 & 0.222 & 0.062 & 0.000 & $(0.091 ; 0.339)$ & 1.3 & 0.620 \\
\hline \multirow[t]{5}{*}{ Perceived behavioral competency (PBC) } & pbc_reducewaste & 0.430 & 0.418 & 0.11 & 0.000 & $(0.198 ; 0.632)$ & 1.2 & 0.698 \\
\hline & pbc_effect & 0.536 & 0.524 & 0.10 & 0.000 & $(0.326 ; 0.729)$ & 1.2 & 0.787 \\
\hline & pbc_local ${ }^{\mathrm{c}}$ & 0.184 & 0.178 & 0.12 & 0.124 & $(-0.051 ; 0.414)$ & 1.1 & 0.446 \\
\hline & pbc_planeimport ${ }^{d}$ & 0.134 & 0.130 & 0.13 & 0.298 & $(-0.115 ; 0.389)$ & 1.2 & 0.487 \\
\hline & pbc_season & 0.230 & 0.226 & 0.13 & 0.079 & $(-0.020 ; 0.494)$ & 1.2 & 0.566 \\
\hline
\end{tabular}

m, mean; sd, standard deviation.

${ }^{a}$ Complete bootstrapping (option: no significant sign changes, 5.000 samples).

${ }^{b}$ Method: bias-corrected and accelerated Bootstrap.

${ }^{c}$ Outer loading, mean: 0.433 ( $p$-value: 0.000).

${ }^{d}$ Outer loading, mean: 0.473 ( $p$-value: 0.000 ).

Source: own data and calculations.

social Norm and Climate Attitude indicator weights as well as pbc_reducewaste and pbc_effect are significant at a level of $0.1 \%$. In contrast, pbc_season is only significant at a $10 \%$ significance level. Thus, all these indicators contribute to forming the constructs. Since the weights are standardized, the outer weights express each indicators relative contribution to the construct. Thus, norm_all has the highest relative importance in forming the construct Subjective and social Norm, and attitude_importance in constructing Climate Attitudes. The outer weights of the indicators pbc_local and pbc_planeimport are not significant. In the case of non-significant indicator weights Hair et al. (2017) recommend to not automatically interpret this outcome as indicative of poor measurement model quality. Instead, the indicators absolute contribution to its construct should be considered by analyzing the formative indicator's outer loadings and its significance. If an outer loading is smaller than 0.5 it should be considered to remove it from the model. Although the outer loadings of both indicators are slightly below $0.5(0.433 / 0.473)$, we kept them in the model since the outer loadings are highly significant $(p<0.000)$ and the variables are assumed to be relevant for the $P B C$-construct.

\section{Evaluation of the Structural Model}

Since the examined reflective and formative constructs show satisfactory levels of quality, the measurement model is evaluated in the next step. Therefore, presence of collinearity, significance of path coefficients, R2, effect size (f2) and predictive relevance (Stone-Geisser's Q2) are assessed and the results are summarized in Table 8 and Figure 3. Since the VIF values of all exogenous variables are smaller than a critical level of 5 , there is no indication of collinearity among the predictors.

The path coefficients of Subjective and social Norm and Climate Attitude are highly significant $(p<0.000)$ and consequently have a significant influence on Intention of climatefriendly food consumption behavior. This is also proven by the confidence intervals, which do not inlcude zero. For both variables the effect is positive. In the case of Climate Attitude a one-unit increase of this latent variable increases intention by 0.501 ceteris paribus. Accordingly, this variable also has the strongest effect, followed by the construct Subjective and social Norm (0.356). The coefficient of $P B C$ is significant at a $10 \%$ level. Thus, this construct has a tendency to have a small and positive influence on intention (0.074).

In total, the three exogenous constructs Subjective Norm, Climate Attitudes and Perceived Behavioral Competency explain $R^{2}=62.1 \%$ of the variance of the endogenous construct Intention, indicating good explanatory power of the model. Addtionally, the $f^{2}$ effect size can be used to evaluate whether a specified exogenous variable has a substantive effect on the Intention-model by observing the change in the $R^{2}$ value when the respective construct is excluded from the model. The effect size of Climate Attitude can be considered as large $\left(f_{\mathrm{CA}}^{2}=0.423\right)$ and the effect size of Subjective and social Norms as medium $\left(f_{\mathrm{SN}}^{2}\right.$ $=0.238$ ). However, since $f^{2}$ of Perceived Behavioral Competency (0.012) is smaller than 0.02 , we found no substantive impact of this construct on the endogenous variable. Finally, predictive relevance was checked using Stone-Geisser's $\mathrm{Q}^{2}$. Since this value is larger than zero, the path model's predictive relevance for the reflective, endogenous construct Intention can be confirmed.

On the basis of the described results we can confirm $\mathrm{H} 1$ and $\mathrm{H} 2$, since we found that the stronger the Subjective and social Norm and the more positive the Climate Attitudes are, the greater the Intention to consume climate-friendly food. However, we have to reject $\mathrm{H} 3$ since we could not find a substantive effect of the construct Perceived Behavioral Competency on Intention.

Addtionally, to check if data is homogenous with respect to different socio-demographic groups multigroup analysis for sex 
TABLE 8 | Results of the structural model.

\begin{tabular}{|c|c|c|c|c|c|c|c|}
\hline $\begin{array}{l}\text { Exogenous construct } \\
\text { Desired value }\end{array}$ & Path coefficient & $\mathrm{m}^{\mathrm{a}}$ & $s^{a}$ & $p$-value ${ }^{a}$ & $\begin{array}{c}\text { Confidence interval } \mathrm{a}^{\mathrm{a}, \mathrm{b}} \\
(2.5 \% ; 97.5 \%)\end{array}$ & $\begin{array}{c}\text { Effect size } f^{2} \\
\text { Min. }>0.02\end{array}$ & $\begin{array}{l}\text { VIF } \\
<5\end{array}$ \\
\hline Subjective and social norm & 0.356 & 0.355 & 0.043 & 0.000 & $(0.277 ; 0.446)$ & 0.238 & 1.4 \\
\hline Perceived behavioral & 0.074 & 0.080 & 0.038 & 0.051 & $(-0.007 ; 0.141)$ & 0.012 & 1.2 \\
\hline
\end{tabular}

competency

$R^{2}=0.621$, Stone-Geisser's $Q^{2}$-value $=0.512($ desired value $>0$ )

m, mean; sd, standard deviation.

${ }^{a}$ Complete bootstrapping (option: no significant sign changes, 5,000 samples).

${ }^{b}$ Method: bias-corrected and accelerated Bootstrap.

Source: own data set and calculations.

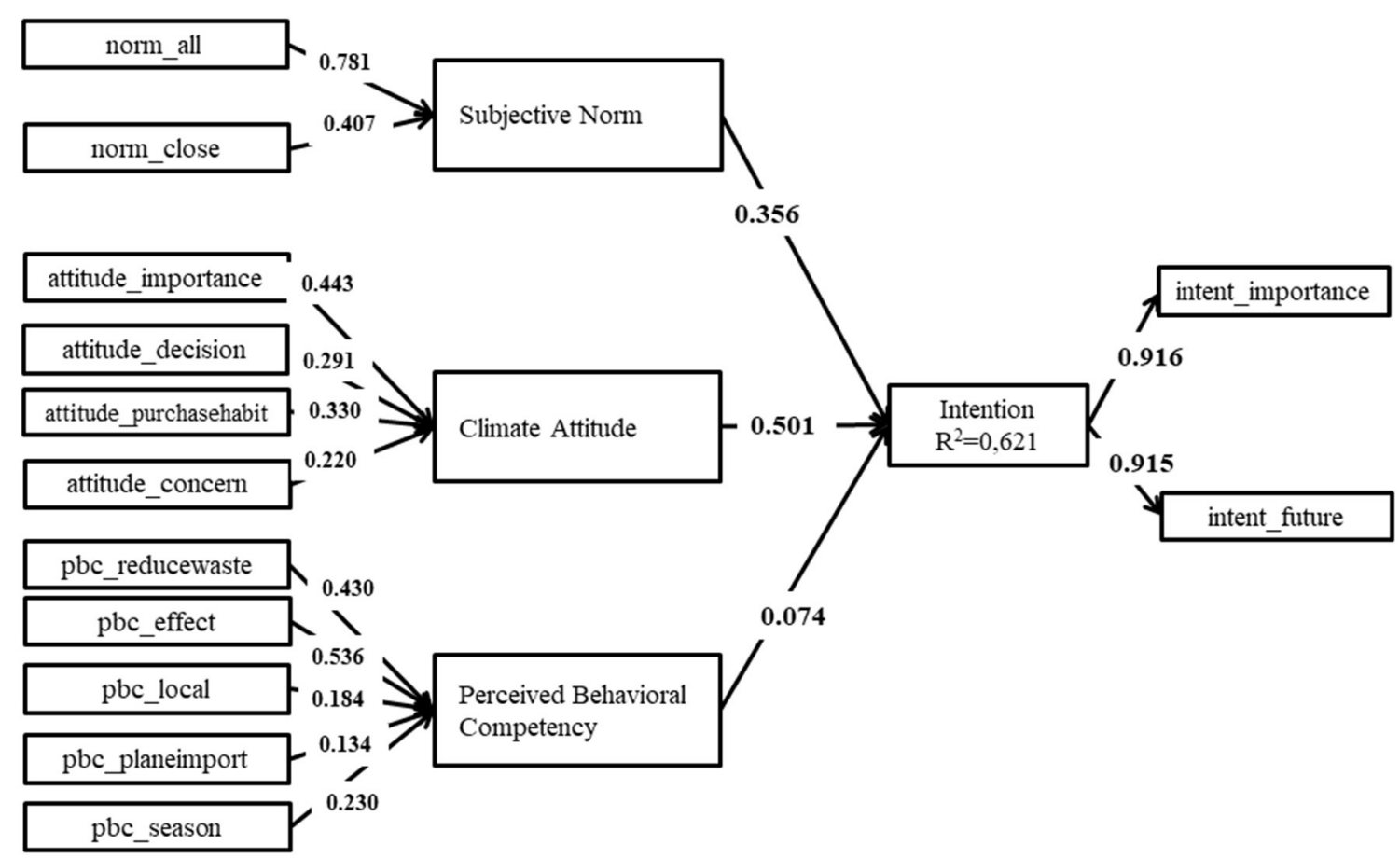

FIGURE 3 | PLS model for Intention of climate-friendly food consumption behavior.

and age groups was conducted. The method makes it possible to check if the specified data groups have significant differences in their group-specific parameter estimates (Hair et al., 2017). However, we did not find any clear differences between the different groups.

\section{DISCUSSION}

Motivated by a proven mitigation potential of changing personal diets and a reported positive intention of consumers to act, the aim of this study was, to analyze the factors which influence consumers' behavioral intentions toward climate-friendly food consumption. Using an extended model of the Theory of Reasoned Action a large positive effect of Climate Attitudes and a medium positive effect of Subjective and social Norm on consumers' behavioral intention toward climate-friendly food consumption was proven. Similar results have been also described in other environment-related fields like the intention toward the purchase or use of green or energy-efficient products or technologies or transportation (Tikir and Lehmann, 2011; Ha and Janda, 2012; Mishra et al., 2014; Paul et al., 2016; Nguyen et al., 2018; Rahimah et al., 2018). Thus, this study showed that in the case of food consumption, individuals intend to behave environmental friendly when they positively appraise this behavior and when they think that people who are important to them believe they should behave in this way. Fishbein (1979) points out the relative importance of the influence of attitude and Subjective and social Norm depends in part on the intention under investigation. In this respect studies from other environment-related fields often found a higher influence of attitude toward the intention compared to the influence of 
Subjective and social Norms (e.g., Tikir and Lehmann, 2011; Mishra et al., 2014; Paul et al., 2016). This was also the case in this study. To further induce climate-friendly food consumption behavior, it is particularly important to point out the positive sides of climate-friendly food consumption, for example in the public debate about climate change. In this respect it is especially important to sensitize consumers to the link between personal diets and climate change so people can connect their own food consumption behavior with their personal GHG mitigation potential. For this purpose, the introduction of carbon labels on food products could be beneficial, since they are able to help consumers to identify climate-friendly food products (EmbergerKlein et al., 2015).

Given the medium high influence of Subjective and social Norm, other strategies in this context are working with peer groups (Tikir and Lehmann, 2011) or using consumerbased incentives which reward beneficial behaviors instead of sanctioning disadvantageous behavior (Liverani, 2009; Tikir and Lehmann, 2011). Specifically in the field of food consumption behavior, there are additionally several studies which investigated the effect of social-norm-based-messages [for a review see Robinson (2015)]. These are messages which provide subjects with information proposing that other individuals eat e.g., a healthy diet. These studies can help researchers understand whether such messages affect real behavior, how long potential effects may last, and whether these kinds of messages are more efficient than simple reminders to consume healthy foods (Robinson, 2015). Even though the results of interventional studies testing such messages in the field of eating behavior are mixed (Robinson, 2015), evaluating the effect of socialnorm-based messages can be an interesting research target for future studies in the field of climate-friendly food consumption. Especially, as healthy and climate-friendly food consumption often go hand-in-hand (e.g., eating more fruit and vegetables saves GHG emissions and is healthy) studies testing the combined effect of both arguments may be worthwhile. Therefore, laboratory experiments and longitudinal studies, as Robinson (2015) suggests for the field of eating behavior, are an interesting methodological approach.

Additionally, in the present study a direct effect of Perceived Behavioral Competency regarding the identification of climatefriendly food on the intention to consume climate-friendly food was proposed. The hypothesis was based on different studies which indicate a positive influence of behavioral competency on environmentally responsible behavior (e.g., De Young, 1988; Corral-Verdugo, 1997; Aitken et al., 2016). However, in this study only a small positive, but not substantial influence of the $P B C$-construct on intention toward climate-friendly food consumption was found. There could be several reasons for this: To begin with, the items measuring Perceived Behavioral Competency had a strong focus on fruit and vegetables, since these are integral components of a climate-friendly diet. However, procedural knowledge on wider or further aspects of climate-friendly food consumption (e.g., meat or dairy products reduction) may better predict Intention. Additionally, Aitken et al. (2016) found that perceived competency directly influences environmentally responsible behavior only in the case of difficult behavior, but not in the case of easy behavior. Due to the results of the descriptive statistics it may be assumed that climate-friendly food consumption was not perceived as very difficult behavior by the respondents. In this case it might be worthwhile to test whether there is an indirect effect of Perceived Behavioral Competency, which is mediated through autonomous and controlled motivation, as Aitken et al. (2016) showed in their study.

Besides these main findings, we showed that Intention toward climate-friendly food consumption varies between different socio-demographic groups, for example between men and women or individuals of different age groups. These results are consistent with other studies dealing with aspects of climatefriendly food consumption (e.g., Gifford and Comeau, 2011; Gifford and Chen, 2017). Due to these variations it would be useful to follow the suggestion of Gifford and Comeau (2011). They recommended incorporating messages which include elements designed to enhance the intentions of individuals to engage in climate-friendly actions especially in media which are heavily used by groups with low intention levels (e.g., men and younger people). Such messages could e.g., point out the positive aspects of climate-friendly food consumption or use norm-based-strategies. Following the suggestion of Untaru et al. (2016) we included socio-demographic variables in our theoretical framework by investigating if pre-defined sociodemographic groups have significant differences in their groupspecific PLS parameter estimates. However, we did not find any clear differences in the parameter estimates of the factors which influence Intention between the different socio-demographic groups using multigroup analysis.

Limitations in this study indicate the need for further research: first, in this work individuals' Intention of climate-friendly food consumption was analyzed instead of real behavior. However, intention does not always lead to actual behavior (Davies et al., 2002). Thus, future studies could include individuals' actual food consumption behavior to test the full TRA framework. Given the complexity of personal diets as well as the variation of GHG emissions in food products (Hedenus et al., 2014), this target is difficult to achieve, especially when an individual's entire diet is under consideration. In this case large nutritional studies like the National Food Consumption Study (Nationale Verzehrsstudie) in Germany can serve as guides for designing future studies [Max Rubner Insitut (MRI), 2008]. To reduce the complexity of the task, researchers could focus on specific components of personal diets which are known to have large climate impacts (e.g., meat or dairy products consumption). Further, social desirability might play a role in our results (Randall and Fernandes, 1991; Untaru et al., 2016), since we used a self-report survey to investigate individuals' intention within a face-to-face survey. This implies direct contact between a respondent and the interviewer. Thus, future studies could use survey forms which allow more anonymity like e.g., an online survey. This could at least partly reduce the social desirability bias. Finally, our model accounted for $62 \%$ of the explained variance in Intention of climate-friendly food consumption. Even though this indicates good explanatory power of the model, it seems necessary to detect further variables which affect Intention and include them in the TRA framework. This can help to further enhance climate-friendly food consumption behavior and exhaust the 
mitigation potential of personal diets. Suggestions for further important antecedents of climate-friendly food consumption can be found in studies dealing with environmental- or climaterelated behavior. For example, Untaru et al. (2016) showed that by expanding the proposed TRA model incorporating the variables: environmental concern and doing the activity in daily life, can enhance the predictive power of the proposed TRA model. Also the study by Gifford and Chen (2017) gives valuables insights concerning further antecedents of climate-friendly food consumption Intentions. They found: Denial, Conflicting goals, Aspirations, and Tokenism to be significantly correlated with mitigate food choice intentions. Another limitation of the study lies in the operationalization of Climate Attitudes. To measure Climate Attitudes a shortened version of the Green Consumption Values developed by Haws et al. (2014) was used and the wording of the items was adapted to the focus of this study. While the original scale by Haws et al. (2014) is a validated scale, the changes have not been validated yet. Adapting existing scales to the focus of a study has been realized in previous studies on climate attitudes (e.g., Tobler et al., 2012). Additionally-and most importantly-according to Fishbein and Ajzen (1975) behavior-specific attitudes are more predictive of intention, than are generic attitudes (Gifford et al., 2011). Thus, a clear reference to "climate" in the formulation of the items used in the study on hand does follow these recommendations. Nevertheless, it is advisable to use validated scales from other studies to measure climate attitudes (e.g., Tobler et al., 2012) in future studies or to validate the adaption of existing scales before carrying out the main survey.

Nevertheless, by using a theory-driven approach our study could point out important factors which influence the Intention toward climate-friendly food consumption. Knowing that Climate Attitudes and Subjective and social Norms are able to explain a large portion of variance in Intention, it is possible to derive measures for behavioral change with respect to food consumption. Promising measures are for example to sensitize consumers to the link between personal diets and climate change e.g., by introducing carbon labels, by giving targeted information to groups with low intention levels, by working with peergroups or by using social-norm based information strategies.

\section{REFERENCES}

Aitken, N. M., Pelletier, L. G., and Baxter, D. E. (2016). Doing the difficult stuff: influence of self-determined motivation toward the environment on transportation proenvironmental behavior. Ecopsychology 8, 153-162. doi: $10.1089 /$ eco.2015.0079

Ajzen, I. (1985). "From Intentions to actions: a theory of planned behavior," in Action Control: From Cognition to Behavior, eds J. Kuhl and J. Beckmann (Berlin, Heidelberg: Springer), 11-39. doi: 10.1007/978-3-642-69746-3_2

Ajzen, I. (1991). The theory of planned behavior. Organiz. Behav. Hum. Decis. Process. 50, 179-211. doi: 10.1016/0749-5978(91)90020-T

Bamberg, S., Hunecke, M., and Blöbaum, A. (2007). Social context, personal norms and the use of public transportation: two field studies. J. Environ. Psychol. 27, 190-203. doi: 10.1016/j.jenvp.2007.04.001

Boßow-Thies, S., and Panten, G. (2009). "Analyse kausaler Wirkungszusammenhänge mit Hilfe von Partial Least Squares (PLS)”,
Given the mitigation potential of personal diets and the described positive intention of individuals to act, future actions in this direction of all responsible actors in food-related value chains are very valuable.

\section{DATA AVAILABILITY STATEMENT}

The raw data supporting the conclusions of this article will be made available by the authors, without undue reservation.

\section{ETHICS STATEMENT}

Ethical review and approval was not required for the study on human participants in accordance with the local legislation and institutional requirements. Written informed consent for participation was not required for this study in accordance with the national legislation and the institutional requirements.

\section{AUTHOR CONTRIBUTIONS}

$\mathrm{AE}-\mathrm{K}$ and $\mathrm{KM}$ contributed to the development of the ideas and the design of the study. AE-K collected the data and performed the data analysis. AE-K and JS wrote the manuscript, which was revised by KM. All authors have read and approved the final manuscript.

\section{FUNDING}

This work was supported by the German Federal Ministry of Education and Research (contract code: 17004X11). The authors acknowledge this financial support but are solely responsible for the content of this manuscript. This work was also funded by the Open Access Publication Fund of Weihenstephan-Triesdorf University of Applied Sciences.

\section{ACKNOWLEDGMENTS}

We want to thank the students, which helped us to collect the data of this study. in Methodik der Empirischen Forschung, eds S. Albers, D. Klapper, U. Konradt, A. Walter, and J. Wolf (Wiesbaden: Gabler Verlag), 365-380. doi: 10.1007/978-3-322-96406-9_24

British Standards Institution (2012). PAS 2050-1: 2012: Assessment of life Cycel Greenhouse Gas Emissions From Horticultural Products. London.

Corral-Verdugo, V. (1997). Dual "realities" of conservation behaviors: self-reports vs observations of re-use and recycling behavior. J. Environ. Psychol. 17, 135-145. doi: 10.1006/jevp.1997. 0048

Davies, J., Foxall, G. R., and Pallister, J. (2002). Beyond the intention-behaviour mythology. Marketing Theory 2, 29-113. doi: 10.1177/14705931020020 01645

De Young, R. (1988). Exploring the difference between recyclers and non-recyclers: the role of information. J. Environ. Syst. 18, 341-351. doi: 10.2190/FBQC-5V5D-HHVCV6X8 
Dirks, H., Kaiser, S., Klose, G., Pfeiffer, I., and Backhaus, M. (2010). Verbrauchermonitoring -Perspektiven der Verbraucher zum Klimaschutz: Mobilität \& Ernährung. Berlin: im Auftrag des Verbraucherzentrale Bundesverbandes e.V.

Emberger-Klein, A., Ergül, R., Mempel, H., and Menrad, K. (2015). Carbon-Footprint-Analysen entlang der Wertschöpfungsketten von Obst und Gemüse an ausgewählten Beispielen sowie Erarbeitung eines entsprechenden Zertifizierungs- und Labellingsystems. Gekürzte Fassung des Schlussberichts an das BMBF (Förderkennzeichen: 17004X11). Straubing: Hochschule Weihenstephan-Triesdorf.

European Union (2021). Climate Change. Available online at: https://ec.europa. eu/clima/sites/default/files/support/docs/report_2021_en.pdf (accessed August 25, 2021).

Faber, J., Schroten, A., Bles, M., Sevenster, M., Markowska, A., Smit, M., et al. (2012). Behavioural climate change mitigation. Options and their appropriate inclusion in quantitative longer term policy scenarios. Main Report. CE Delft, Netherlands

Fishbein, M. (1979). Beliefs, attitudes and values. Nebraska Symp. Motiv. 27, 65-116.

Fishbein, M., and Ajzen, I. (1975). Belief, Attitude, Intention, and Behavior: An Introduction to Theory and Research. Reading, MA: Addison-Wesley.

Gifford, R., and Chen, A. K. S. (2017). Why aren't we taking action? Psychological barriers to climate-positive food choices. Clim. Change 140, 165-178. doi: 10.1007/s10584-016-1830-y

Gifford, R., and Comeau, L. A. (2011). Message framing influences perceived climate change competence, engagement, and behavioral intentions. Glob. Environ. Change 21, 1301-1307. doi: 10.1016/j.gloenvcha.2011.06.004

Gifford, R., Kormos, C., and McIntyre, A. (2011). Behavioral dimensions of climate change: drivers, responses, barriers, and interventions. Wiley Interdiscipl. Rev. Clim. Change 2, 801-827. doi: 10.1002/wcc.143

Green, R., Milner, J., Dangour, A. D., Haines, A., Chalabi, Z., Markandya, A., et al. (2015). The potential to reduce greenhouse gas emissions in the UK through healthy and realistic dietary change. Clim. Change 129, 253-265. doi: $10.1007 /$ s 10584-015-1329-y

Ha, H.-Y., and Janda, S. (2012). Predicting consumer intentions to purchase energy-efficient products. J. Consumer Market. 29, 461-469. doi: 10.1108/07363761211274974

Hair, J., Hult, T., Ringle, C., and Sarstedt, M. (2017). A Primer on Partial Least Squares Structural Equation Modeling (PLS-SEM), 2nd Edn. Los Angeles, CA; Londond; New Delhi; Singapore; Washington, DC, Melbourne: Sage.

Haws, K. L., Winterich, K. P., and Naylor, R. W. (2014). Seeing the world through GREEN-tinted glasses: green consumption values and responses to environmentally friendly products. J. Consumer Psychol. 24, 336-354. doi: $10.1016 /$ j.jcps.2013.11.002

Hedenus, F., Wirsenius, S., and Johansson, D. J. A. (2014). The importance of reduced meat and dairy consumption for meeting stringent climate change targets. Clim. Change 124, 79-91. doi: 10.1007/s10584-014-1104-5

Henseler, J., Ringle, C. M., and Sinkovics, R. R. (2009). "The use of partial least squares path modeling in international marketing," in New Challenges to International Marketing (London: Emarald), 277-319. doi: 10.1108/S1474-7979(2009)0000020014

Huber, F., Herrmann, A., Meyer, F., Vogel, J., and Vollhardt, K. (2007). Kausalmodellierung mit Partial Least Squares: Eine anwendungsorientierte Einführung. Wiesbaden: Betriebswirtschaftlicher Verlag Dr. Th. Gabler| GWV Fachverlage GmbH Wiesbaden.

Kainz, U., Klein, A., and Menrad, K. (2014). Kauf- und Zahlungsbereitschaft für Polyamide aus heimischen Nachwachsenden Rohstoffen. Teilprojekt 10 des Graduiertenkollegs BayReChem 2050. Final Report. Straubing, Germany, Abschlussbericht.

Kögl, H., and Tietze, J. (Ed.). (2010). Regionale Erzeugung, Verarbeitung und Vermarktung von Lebensmitteln: Studie im Auftrag des Bundesministeriums für Landwirtschaft, Ernährung und Verbraucherschutz; Forschungsberichte der Professur für Landwirtschaftliche Betriebslehre und Management, Vol. 2. Rostock: Universität Rostock.

Liverani, A. (2009). "Climate change and individual behavior. Considerations for policy; background paper to the 2010 World Development Report," in Policy Research Working Paper 5058. World Bank. doi: 10.1596/1813-9450-5058
Mäkiniemi, J.-P., and Vainio, A. (2013). Moral intensity and climate-friendly food choices. Appetite 66, 54-61. doi: 10.1016/j.appet.2013.01.026

Max Rubner Insitut (MRI) (2008). Nationale Verzehrsstudie II. Ergebnisbericht, Teil 2, Karlsruhe: Max Rubner Insitut. doi: 10.1007/s12082-008-0148-1

Mishra, D., Akman, I., and Mishra, A. (2014). Theory of reasoned action application for green information technology acceptance. Comput. Hum. Behav. 36, 29-40. doi: 10.1016/j.chb.2014.03.030

Nguyen, Q. A., Hens, L., MacAlister, C., Johnson, L., Lebel, B., and Bach Tan, S. (2018). Theory of reasoned action as a framework for communicating climate risk: A case study of schoolchildren in the Mekong Delta in Vietnam. Sustainability. 10, 1-6. doi: 10.3390/su10062019

Nitzl, C. (2010). Eine Anwenderorientierte Einführung in die Partial Least Square(PLS)-Methode, Arbeitspapier Nr. 21. Hamburg: Universität Hamburg. doi: $10.2139 /$ ssrn.2097324

Paul, J., Modi, A., and Patel, J. (2016). Predicting green product consumption using theory of planned behavior and reasoned action. J. Retail. Consumer Serv. 29, 123-134. doi: 10.1016/j.jretconser.2015.11.006

Rahimah, A., Khalil, S., Cheng, J. M.-S., Tran, M. D., and Panwar, V. (2018). Understanding green purchase behavior through death anxiety and individual social responsibility: Mastery as a moderator. J. Consum. Behav. 17, 477-490. doi: $10.1002 / \mathrm{cb} .1733$

Randall, D., and Fernandes, M. (1991). Social desirability response bias. J. Business Ethics 10, 805-817. doi: 10.1007/BF00383696

Ringle, C., Wende, S., and Becker, J.-M. (2015). SmartPLS 3. Boenningstedt: SmartPLS GmbH. Available online at: http://www.smartpls.com (accessed July 7, 2018).

Robinson, E. (2015). Perceived social norms and eating behaviour: an evaluation of studies and future directions. Physiol. Behav. 152, 397-401. doi: 10.1016/j.physbeh.2015.06.010

Scarborough, P., Appleby, P. N., Mizdrak, A., Briggs, A. D. M., Travis, R. C., Bradbury, K. E., et al. (2014). Dietary greenhouse gas emissions of meat-eaters, fish-eaters, vegetarians and vegans in the UK. Clim. Change 125, 179-192. doi: 10.1007/s10584-014-1169-1

Sharp, A., and Wheeler, M. (2013). Reducing householders' grocery carbon emissions: carbon literacy and carbon label preferences. Austral. Market. J. 21, 240-249. doi: 10.1016/j.ausmj.2013.08.004

Sheppard, B., Hartwick, J., and Warshaw, P. (1988). The theory of reasoned action: a meta-analysis of past research with recommendations for modifications and future research. J. Consumer Res. 15, 325-343. doi: 10.1086/2 09170

Soode, E., Lampert, P., Weber-Blaschke, G., and Richter, K. (2015). Carbon footprints of the horticultural products strawberries, asparagus, roses and orchids in Germany. J. Clean. Prod. 87, 168-179. doi: 10.1016/j.jclepro.2014.09.035

Sundblad, E.-L., Biel, A., and Gärling, T. (2014). Intention to change activities that reduce carbon dioxide emissions related to worry about global climate change consequences. Eur. Rev. Appl. Psychol. 64, 13-17. doi: 10.1016/j.erap.2011.12.001

Theurl, M. (2008). $\mathrm{CO}_{2}$-Bilanz der Tomatenproduktion: Analyse acht verschiedener Produktionssysteme in Österreich, Spanien und Italien. Social Ecology Working Paper10. Wien: Klagenfurt University.

Tikir, A., and Lehmann, B. (2011). Climate change, theory of planned behavior and values: a structural equation model with mediation analysis. Clim. Change 104, 389-402. doi: 10.1007/s10584-010-9937-z

Tobler, C., Visschers, V. H. M., and Siegrist, M. (2012). Addressing climate change: determinants of consumers' willingness to act and to support policy measures. J. Environ. Psychol. 32, 197-207. doi: 10.1016/j.jenvp.2012.02.001

Untaru, E.-N., Ispas, A., Candrea, A. N., Luca, M., and Epuran, G. (2016). Predictors of individuals' intention to conserve water in a lodging context: the application of an extended Theory of Reasoned Action. Int. J. Hosp. Manag. 59, 50-59. doi: 10.1016/j.ijhm.2016.09.001

van der Linden, S. (2014). The social-psychological determinants of climate change mitigation intentions and behaviours: a domain - context -behaviour (DCB) model (Doctoral Dissertation). London School of Economics and Political Science, London, United Kingdom. doi: 10.2139/ssrn.2469464

Verbraucheranalyse (2012). Verbraucheranalyse 2012 Klasskik III-Maerkte Strukturanalyse. Hamburg. 
Conflict of Interest: JS is employed by GreenSurvey - Institut für Marktforschung Prof. Dr. Menrad GmbH.

The remaining authors declare that the research was conducted in the absence of any commercial or financial relationships that could be construed as a potential conflict of interest.

Publisher's Note: All claims expressed in this article are solely those of the authors and do not necessarily represent those of their affiliated organizations, or those of the publisher, the editors and the reviewers. Any product that may be evaluated in this article, or claim that may be made by its manufacturer, is not guaranteed or endorsed by the publisher.

Copyright $\odot 2021$ Emberger-Klein, Schöps and Menrad. This is an open-access article distributed under the terms of the Creative Commons Attribution License (CC BY). The use, distribution or reproduction in other forums is permitted, provided the original author(s) and the copyright owner(s) are credited and that the original publication in this journal is cited, in accordance with accepted academic practice. No use, distribution or reproduction is permitted which does not comply with these terms. 